\title{
Dietary L-arginine supplementation attenuates lipopolysaccharide-induced inflammatory response in broiler chickens
}

\author{
Jianzhuang $\operatorname{Tan}^{1,2}$, Shasha Liu ${ }^{1}$, Yuming Guo ${ }^{1 *}$, Todd J. Applegate ${ }^{2 *}$ and Susan D. Eicher ${ }^{3}$ \\ ${ }^{1}$ State Key Laboratory of Animal Nutrition, College of Animal Science and Technology, China Agricultural University, \\ Beijing 100193, People's Republic of China \\ ${ }^{2}$ Department of Animal Sciences, Purdue University, West Lafayette, IN 47907, USA \\ ${ }^{3}$ Livestock Behavioral Research Unit, United State Department of Agriculture, Agricultural Research Service, \\ West Lafayette, IN, USA
}

(Submitted 6 June 2013 - Final revision received 8 October 2013 - Accepted 13 October 2013 - First published online 13 January 2014)

\section{Abstract}

In the present study, two experiments were conducted to investigate the effect of dietary L-arginine (Arg) supplementation on the inflammatory response and innate immunity of broiler chickens. Expt 1 was designed as a $2 \times 3$ factorial arrangement ( $n 8$ cages/treatment; $n 6$ birds/cage) with three dietary Arg concentrations (1.05, 1.42 and 1.90\%) and two immune treatments (injection of lipopolysaccharide (LPS) or saline) given at an interval of $48 \mathrm{~h}$ between 14 and $21 \mathrm{~d}$ of age. In Expt 2, correlation between dietary Arg concentration (0.99, 1.39, $1.76,2.13$ or $2.53 \%$ ) and percentage of circulating B cells (percentage of circulating lymphocytes) was determined. In Expt 1, LPS injection decreased body-weight gain and feed intake and increased feed conversion ratio of the challenged broilers $(14-21 \mathrm{~d} ; P<0 \cdot 05)$. LPS injection suppressed $(P<0.05)$ the percentages of splenic $\mathrm{CD} 11^{+}$and B cells (percentages of splenic lymphocytes) and phagocytic activity of splenic heterophils and macrophages; Arg supplementation linearly decreased the percentages of CD $11^{+}, \mathrm{CD} 14^{+}$and B cells in the spleen $(P<0 \cdot 10)$. LPS injection increased $(P<0 \cdot 05)$ the expression of $I L-1 \beta$ and $I L-6$ mRNA in the spleen and caecal tonsils. Arginine supplementation decreased $(P<0.05)$ the expression of $I L-1 \beta$, Toll-like receptor 4 (TLR4) and PPAR- $\gamma$ mRNA in the spleen and $I L-1 \beta, I L-10, T L R 4$ and $N F-\kappa B$ mRNA in the caecal tonsils. In Expt 2, increasing dietary Arg concentrations linearly and quadratically reduced the percentage of circulating B cells $(P<0 \cdot 01)$. Collectively, Arg supplementation attenuated the overexpression of pro-inflammatory cytokines probably through the suppression of the TLR4 pathway and $\mathrm{CD}_{1} 4^{+}$cell percentage. Furthermore, excessive Arg supplementation (1.76\%) suppressed the percentages of circulating and splenic B cells.

Key words: L-Arginine: Broilers: Lipopolysaccharide: TLR4

L-Arginine (Arg) is an essential amino acid for chickens and is a conditionally essential amino acid for mammals under surgery, sepsis and many other pathological conditions ${ }^{(1-3)}$. It is used for the synthesis of $\mathrm{NO}$ and polyamines, which are involved in the modulation of inflammation and wound healing ${ }^{(2,4,5)}$. Although Arg has been used in chickens to enhance the immune function during immunological stress ${ }^{(6)}$, there is still no consensus on the benefits of supplementing Arg beyond the $\mathrm{NRC}^{(7)}$-recommended concentration ${ }^{(8)}$. In normal animal-rearing conditions, the animal is inevitably confronted with various microbial challenges that often will not result in clinical disease. However, these microbial challenges lead to a series of immune responses, including mild inflammatory responses, which changes the partitioning of nutrients away from body protein accretion to support the immune responses, thereby reducing the growth potential of the animal ${ }^{(9)}$. Studies in piglets and chickens have demonstrated that dietary Arg supplementation could enhance the immune functions of animals under immunological stress ${ }^{(10,11)}$. Furthermore, a study in mice has shown that Arg administration decreases the expression of proinflammatory cytokines in a dextran sulphate sodium-induced inflammatory bowel disease model ${ }^{(12)}$. However, few studies have been conducted to determine the effect of dietary Arg supplementation on the inflammatory response in chickens.

\footnotetext{
Abbreviations: Arg, L-arginine; BW, body weight; FCR, feed conversion ratio; FI, feed intake; FSC, forward-scatter characteristics; iNOS, inducible NO synthase; LBP, LPS-binding protein; LPS, lipopolysaccharide; MyD88, myeloid differentiation factor 88; PBMC, peripheral blood mononuclear cells; RPMI, Roswell Park Memorial Institute; SSC, side-scatter characteristics; Th, T helper; TIRAP, Toll-IL 1 receptor domain-containing adaptor protein; TLR4, Toll-like receptor 4; TRAM, Toll-IL 1 receptor domain-containing adaptor inducing interferon-related adaptor molecule; TRIF, Toll-IL 1 receptor domain-containing adaptor inducing interferon.
}

*Corresponding authors: Yuming Guo, fax + 86106273 3900, email guoyum@cau.edu.cn; T. J. Applegate, fax +1 7654949346 ,

email applegt@purdue.edu 
$\mathrm{NRC}^{(7)}$ requirements for broilers. An initial basal diet was mixed to contain a formulated Arg of $0.99 \%$. The final diets were obtained by mixing $97.96 \%$ of the basal ration with a premix $(2.04 \%)$ containing different concentrations of Arg and L-alanine. Ingredient formulation, nutrients and analysed dietary Arg concentration in Expt 2 are given in Table 2. At $21 \mathrm{~d}$ of age, a blood sample from one randomly selected bird per replicate was collected from the brachial vein with a heparinised syringe for peripheral blood mononuclear cell (PBMC) isolation.

Animal use and care procedures followed in Expt 1 were approved by the Purdue Animal Care and Use Committee and those followed in Expt 2 were approved by the China Agricultural University Animal Care and Use Committee. Expt 1 and Expt 2 were carried out following the same management procedure. All the chickens were housed in stainless-steel brooders equipped with nipple-type waterers and thermostatically controlled heaters. The temperature was maintained at $37 \pm 1^{\circ} \mathrm{C}$ during the first week and was reduced by $3^{\circ} \mathrm{C}$ each consecutive week until reaching $24^{\circ} \mathrm{C}$. The lighting schedule was $22 \mathrm{~h}$ light $-2 \mathrm{~h}$ dark throughout the experiments. Drinking-water and feed were provided ad libitum. Diet analyses for amino acid concentration were conducted using HPLC (University of Missouri Agriculture Experiment Station Chemistry Laboratory; AOAC International, 2000; method 982.30.E (a, b, c) $)^{(21)}$.

\section{Splenocyte and peripheral blood mononuclear cell} isolation

Splenocyte isolation was carried out as described previously $^{(22)}$ with the following modifications. The spleens were collected immediately after the chicks were killed and placed in sterile Roswell Park Memorial Institute (RPMI) medium in $10 \mathrm{ml}$ tubes kept on ice. After removal of the adherent fat and tissues, a cell suspension was prepared by grinding the spleens through a 60 mesh screen; the cells were centrifuged at $80 \mathrm{~g}$ for $10 \mathrm{~min}$ at $4{ }^{\circ} \mathrm{C}$ and the supernatant was collected into a new $15 \mathrm{ml}$ tube and the pellet discarded. The supernatant was centrifuged at $200 \mathrm{~g}$ for $10 \mathrm{~min}$ at $4^{\circ} \mathrm{C}$. The supernatant was discarded and the pellets were resuspended in $2.5 \mathrm{ml}$ RPMI, after which splenocytes were washed two times. Splenocyte counts and viability were evaluated using Trypan Blue exclusion.

PBMC were isolated from peripheral blood samples using Ficoll density centrifugation according to the method of Long et al. ${ }^{(23)}$. Briefly, blood samples were carefully layered on the top of the Ficoll layer (Histopaque 1077; Sigma Chemical Company) in a $10 \mathrm{ml}$ centrifuge tube (1:1). The tube was centrifuged at $200 \mathrm{~g}$ for $30 \mathrm{~min}\left(25^{\circ} \mathrm{C}\right)$. After centrifugation, the PBMC at the plasma-ficoll interface were collected. Cold RPMI-1640 medium (containing $5.0 \%$ inactivated fetal bovine serum, $100 \mathrm{U}(0.0599 \mathrm{mg})$ penicillin $/ \mathrm{ml}, 100 \mu \mathrm{g}$ streptomycin $/ \mathrm{ml}$ and 10 mM-HEPES) was added to the tube containing the PBMC.

Table 2. Composition of the experimental diets used in Expt 2 ( $\mathrm{g} / \mathrm{kg}$ dry diet)

\begin{tabular}{|c|c|c|c|c|c|}
\hline & \multicolumn{5}{|c|}{ Analysed Arg concentration (\%) } \\
\hline & 0.99 & $1 \cdot 39$ & $1 \cdot 76$ & $2 \cdot 13$ & 2.53 \\
\hline \multicolumn{6}{|l|}{ Ingredients } \\
\hline Maize & $580 \cdot 8$ & $580 \cdot 8$ & $580 \cdot 8$ & $580 \cdot 8$ & $580 \cdot 8$ \\
\hline Soyabean meal, $48 \%$ CP & $110 \cdot 0$ & $110 \cdot 0$ & $110 \cdot 0$ & $110 \cdot 0$ & $110 \cdot 0$ \\
\hline Canola meal & $80 \cdot 0$ & $80 \cdot 0$ & $80 \cdot 0$ & $80 \cdot 0$ & $80 \cdot 0$ \\
\hline Maize gluten meal & $136 \cdot 0$ & $136 \cdot 0$ & $136 \cdot 0$ & $136 \cdot 0$ & $136 \cdot 0$ \\
\hline Soyabean oil & $25 \cdot 0$ & $25 \cdot 0$ & $25 \cdot 0$ & $25 \cdot 0$ & $25 \cdot 0$ \\
\hline Limestone & $13 \cdot 3$ & $13 \cdot 3$ & $13 \cdot 3$ & $13 \cdot 3$ & $13 \cdot 3$ \\
\hline Calcium hydrophosphate & 18.5 & 18.5 & 18.5 & 18.5 & $18 \cdot 5$ \\
\hline L-Lys-HCl & 5.5 & 5.5 & 5.5 & 5.5 & $5 \cdot 5$ \\
\hline DL-Met & 0.9 & 0.9 & 0.9 & 0.9 & 0.9 \\
\hline L-Thr & $0 \cdot 1$ & $0 \cdot 1$ & $0 \cdot 1$ & $0 \cdot 1$ & $0 \cdot 1$ \\
\hline L-Trp & 0.5 & 0.5 & 0.5 & 0.5 & 0.5 \\
\hline Choline chloride & 2.5 & 2.5 & 2.5 & 2.5 & $2 \cdot 5$ \\
\hline $\mathrm{NaCl}$ & $3 \cdot 0$ & 3.0 & $3 \cdot 0$ & $3 \cdot 0$ & 3.0 \\
\hline Vitamin/trace mineral premix ${ }^{*}$ & 3.5 & 3.5 & 3.5 & 3.5 & 3.5 \\
\hline L-Arg & 0.0 & $5 \cdot 1$ & $10 \cdot 2$ & $15 \cdot 3$ & $20 \cdot 4$ \\
\hline L-Ala & $20 \cdot 4$ & $15 \cdot 3$ & $10 \cdot 2$ & $5 \cdot 1$ & 0.0 \\
\hline \multicolumn{6}{|l|}{ Nutrient and energy concentration } \\
\hline ME (MJ/kg)† & $12 \cdot 5$ & 12.5 & 12.5 & 12.5 & $12 \cdot 5$ \\
\hline $\mathrm{CP} \ddagger$ & $202 \cdot 8$ & $202 \cdot 7$ & $202 \cdot 7$ & 202.5 & $202 \cdot 7$ \\
\hline $\mathrm{Ca}$ & $10 \cdot 0$ & $10 \cdot 0$ & $10 \cdot 0$ & $10 \cdot 0$ & $10 \cdot 0$ \\
\hline Non-phytate phosphorus $\dagger$ & 4.5 & 4.5 & 4.5 & 4.5 & 4.5 \\
\hline Lys $\ddagger$ & $11 \cdot 0$ & $11 \cdot 0$ & $10 \cdot 9$ & $10 \cdot 9$ & $11 \cdot 0$ \\
\hline Metł & $4 \cdot 6$ & $4 \cdot 6$ & 4.5 & 4.5 & 4.5 \\
\hline Arg $\ddagger$ & $9 \cdot 9$ & $13 \cdot 9$ & $17 \cdot 6$ & $21 \cdot 3$ & $25 \cdot 3$ \\
\hline
\end{tabular}

$\mathrm{CP}$, crude protein; ME, metabolisable energy.

* Supplied the following per kg complete diet: Cu, $8 \mathrm{mg} ; \mathrm{Zn}, 75 \mathrm{mg} ; \mathrm{Fe}, 80 \mathrm{mg}$; Mn, $100 \mathrm{mg}$; Se, $0.15 \mathrm{mg}$; I, $0.35 \mathrm{mg}$; trans-retinyl acetate, $24 \mathrm{mg}$; cholecalciferol, $6 \mathrm{mg}$; DL- $\alpha$-tocopheryl acetate, $7.2 \mathrm{mg}$; menadione, $1.3 \mathrm{mg}$; thiamin, $2 \mathrm{mg}$; riboflavin, $6 \mathrm{mg}$; cyanocobalamin, $0.025 \mathrm{mg}$; biotin, $0.0325 \mathrm{mg}$; folic acid, $1.25 \mathrm{mg}$; pantothenic acid, $12 \mathrm{mg}$; niacin, $50 \mathrm{mg}$. † Calculated value.

$\ddagger$ Analysed concentrations. 
Then, the cells were washed three times with cold RPMI-1640 medium by centrifugation at $100 \mathrm{~g}$ for $10 \mathrm{~min}\left(4^{\circ} \mathrm{C}\right)$. PBMC counts and viability were evaluated using Trypan Blue exclusion.

\section{Determination of the phagocytic activity of splenocytes}

The phagocytic activity of splenocytes was performed using pHrodo $^{\text {TM }}$ E. coli BioParticles ${ }^{\circledR}$ Phagocytosis Kits (Invitrogen Canada, Inc.). Briefly, $100 \mu \mathrm{l}$ of splenocytes were incubated for $15 \mathrm{~min}$ at $37^{\circ} \mathrm{C}$ with $20 \mu$ l of pHrodo $^{\mathrm{TM}}$ BioParticles $^{\circledR}$ conjugate (Molecular Probes). Control samples were incubated for $15 \mathrm{~min}$ on ice. Then, the samples were washed two times according to the kit instructions, and the cell pellets were resuspended in $0.5 \mathrm{ml}$ of wash buffer for flow cytometric analysis. The samples were analysed using an Accuri ${ }^{\circledR}$ C6 flow cytometer (Accuri Cytometers). Data were collected from 10000 events. The threshold was adjusted to eliminate background fluorescence after the application of a negative control sample. The linear forward-scatter characteristic (FSC) and side-scatter characteristic (SSC) voltages were set to locate the heterophil and macrophage population following the manufacturer's instructions (Invitrogen Canada, Inc.) and as described previously $^{(24)}$. Phagocytic activity is expressed as a percentage of cells that were phagocytic, and phagocytic intensity is expressed as mean fluorescence intensity.

\section{Flow cytometric analysis of immune cell phenotypes}

Splenocytes were stained with chicken CD3 (fluorescein isothiocyanate), chicken Bu-1 (phycoerythrin; PE), human CD14 (PE) and human CD11 (Alexa Fluor ${ }^{\circledR}$ 488) for $30 \mathrm{~min}$ in a water-bath $\left(37^{\circ} \mathrm{C}\right)$. The PBMC were stained with chicken $\mathrm{Bu}-1$ (PE) for $30 \mathrm{~min}$ on ice. The control samples were processed without antibody staining. All the antibodies used in the present study were purchased from Southern Biotech. The CD14 antibodies have been used to label chicken lymphocytes in a previous study ${ }^{(25)}$. The cells were then washed two times with $1 \times$ Hanks balanced salt solution (HBSS), fixed with paraformaldehyde solution (3\% in HBSS) and stored at $4^{\circ} \mathrm{C}$ until further analysis. The samples were analysed using an Accuri ${ }^{\circledR} \mathrm{C} 6$ flow cytometer (Accuri Cytometers). Lymphocytes were gated by FSC and SSC and 10000 gated events were analysed. Briefly, subcellular dead cell debris can be distinguished from single cells by size as they have lower FSC and higher SSC than living cells. Compared with monocytes, lymphocytes have lower FSC and SSC. The threshold was adjusted to eliminate background fluorescence after the application of a negative control sample ${ }^{(24)}$. Cell phenotype data are expressed as a percentage of gated lymphocytes. The percentage of total splenic lymphocytes was based on total isolated splenocytes. The percentage of total peripheral blood lymphocytes was based on total isolated PBMC.

\section{Total RNA extraction and RT}

Total RNA of spleen and caecal tonsils was extracted using TRIzol Reagent (Invitrogen Canada, Inc.) following the manufacturer's protocol. The concentration, quality and integrity of total RNA were evaluated using a spectrophotometer as described previously ${ }^{(26)}$. The total RNA was incubated with DNase I (Sigma Chemical Company) at room temperature for $15 \mathrm{~min}$, and the DNase I was subsequently inactivated by heating the reaction mixture at $70^{\circ} \mathrm{C}$ for $10 \mathrm{~min}$. An RNA amount of $2 \mu \mathrm{g}$ was used for RT using Moloney murine leukaemia virus RT (Promega) with Oligo-dt (Qiagen, Inc.) according to the manufacturer's protocol, and the complementary DNA was stored at $-20^{\circ} \mathrm{C}$.

\section{Real-time quantitative $P C R$}

Real-time quantitative PCR for determining the expression of inflammation-related genes in the spleen and caecal tonsils was carried out using iQ SYBR Green Supermix (BiO-Rad) in a Bio-Rad iQ5 detection system (Bio-Rad Laboratories). The expression of glyceraldehyde-3-phosphate dehydrogenase was considered as an internal control to normalise the amount of starting RNA used for real-time quantitative PCR for each sample. A reaction mixture of $20 \mu \mathrm{l}$ contained $10 \mu \mathrm{l}$ of $\mathrm{iQ}$ SYBR Green Supermix (Bio-Rad), $0.3 \mu \mathrm{m}$ of each forward primer and reverse primer (Table 3 ), and $6 \mu$ l of complementary DNA. Each analysis was carried out in triplicate. The following protocol was used for all the genes: $95^{\circ} \mathrm{C}$ for $5 \mathrm{~min}$; forty cycles of $95^{\circ} \mathrm{C}$ for $10 \mathrm{~s}$ and $55^{\circ} \mathrm{C}$ for $20 \mathrm{~s} ; 72^{\circ} \mathrm{C}$ for $20 \mathrm{~s}$. The standard curve was determined using pooled samples, and the real-time quantitative PCR efficiency for each gene was determined by amplifying a dilution series of complementary DNA $\left(10^{(-1 / \text { slope })}\right)$, and the efficiency values were consistent between the target genes and housekeeping gene. The specificity of the amplified products was evaluated with the melting curve analysis. The abundance of glyceraldehyde-3-phosphate dehydrogenase mRNA as the housekeeping gene was not influenced by the dietary Arg concentration and LPS injection in both the spleen and caecal tonsils (data not shown). The average gene expression relative to the expression of glyceraldehyde-3-phosphate dehydrogenase for each sample was calculated using the $2^{-\Delta \Delta C_{\mathrm{t}}} \operatorname{method}^{(27)}$, and the calibrator for each gene was the average $\Delta C_{\mathrm{t}}$ value of the pooled sample.

\section{Statistical analysis}

The results are reported as means with their standard errors, and all the data were analysed using the GLM procedure of SAS software (SAS Institute, Inc.). Data were subjected to two-way ANOVA in a $2 \times 3$ factorial arrangement with immunological challenge and dietary Arg concentration as the main effects and their interactions. The analysis of interactions was based on a hypothesis that a non-linear response to Arg concentration could potentially interact with LPS; therefore, a polynomial contrast for the dose responsiveness of dietary Arg concentrations was conducted. When interactions were significant, polynomial contrasts were used to determine the linear and quadratic responses of simple means to dietary Arg concentrations within the LPS-injected and saline-injected groups, respectively. When interactions were not significant, the polynomial contrasts were conducted over main effect means for Arg concentrations (averaged over 
Table 3. Primers used in real-time quantitative $\mathrm{PCR}^{\star}$

\begin{tabular}{|c|c|c|}
\hline Target genes & Primer sequence $\left(5^{\prime} \rightarrow 3^{\prime}\right)$ & Accession no. $\dagger$ \\
\hline GAPDH & $\begin{array}{l}\text { F: CCTAGGATACACAGAGGACCAGGTT } \\
\text { R: GGTGGAGGAATGGCTGTCA }\end{array}$ & NM_204305 \\
\hline$T L R 4$ & $\begin{array}{l}\text { F: AGT CTG AAA TTG CTG AGC TCA AAT } \\
\text { R: GCG ACG TTA AGC CAT GGA AG }\end{array}$ & NM_001030693 \\
\hline$N F-\kappa B$ & $\begin{array}{l}\text { F: GTGTGAAGAAACGGGAACTG } \\
\text { R: GGCACGGTTGTCATAGATGG }\end{array}$ & NM205129 \\
\hline PPAR $\gamma$ & $\begin{array}{l}\text { F: GACCTTAATTGTCGCATCCAT } \\
\text { R: CGGGAAGGACTTTATGTATGA }\end{array}$ & AF163811 \\
\hline$I L-1 \beta$ & $\begin{array}{l}\text { F: ACT GGG CAT CAA GGG CTA } \\
\text { R: GGT AGA AGA TGA AGC GGG TC }\end{array}$ & NM_204524 \\
\hline IL-6 & $\begin{array}{l}\text { F: TTTATG GAGAAGACCGTGAGG } \\
\text { R: TGTGGCAGATTGGTAACAGAG }\end{array}$ & NM_204628 \\
\hline$I L-10$ & $\begin{array}{l}\text { F: GCTGTCACCGCTTCTTCACCT } \\
\text { R: GGCTCACTTCCTCCTCCTCATC }\end{array}$ & EF554720.1 \\
\hline
\end{tabular}

LPS treatments). At $14 \mathrm{~d}$ of age, the BW were different between the treatment groups; therefore, $14 \mathrm{~d}$ BW was used as a covariate in the model to analyse the growth performance from 14 to $21 \mathrm{~d}$. Polynomial contrasts were used to determine significant linear, quadratic and cubic responses of circulating $\mathrm{B}$ cells (peripheral blood B cells) to dietary Arg concentrations (analysed dietary Arg concentrations). A $P \leq 0.05$ was considered to be statistically significant, and $0.05<P<0 \cdot 10$ was considered to be a trend towards significance.

\section{Results}

\section{Expt 1}

With the exception of the feed conversion ratio (FCR) and $I L-1 \beta$ mRNA expression in the caecal tonsils, no significant Arg $\times$ LPS interactions were observed for any of the other measured characteristics.

\section{Growth performance}

The growth performance of chickens between 14 and $21 \mathrm{~d}$ of age is summarised in Table 4. Dietary Arg supplementation significantly increased $(P<0.05)$ the BW of chickens at $14 \mathrm{~d}$ of age. Compared with the saline injection, LPS injection significantly decreased $(P<0.05)$ the BW gain by $9.36 \%$ and feed intake (FI) by $14.87 \%$ in the LPS-challenged chickens, while dietary Arg supplementation significantly increased $(P<0.05)$ the BW gain and FI of the chickens. An interaction between LPS challenge and dietary Arg concentration was significant $(P<0.05)$ for the FCR, wherein chickens in the control group (1.05\% Arg) had the highest FCR and those in the challenged group (1.90\% Arg) had the lowest FCR compared with all the other groups. The FCR was linearly and quadratically $(P<0.05)$ reduced by increasing dietary Arg concentrations in the saline-injected groups. Increasing dietary Arg concentrations had a more pronounced effect in the non-challenged chickens than in the LPS-challenged chickens.

\section{Determination of the phagocytic activity of splenocytes}

LPS injection significantly suppressed $(P<0.05)$ the percentage of phagocytic heterophils and macrophages (Table 5). However, no significant effect of dietary Arg concentration on phagocytic capacity was observed $(P>0.05)$.

Table 4. Growth performance of broilers fed diets containing 1.05, 1.42 or $1.90 \%$ arginine (Arg) with or without lipopolysaccharide (LPS) challenge from 14 to $21 \mathrm{~d}$ of age (Expt 1)*

(Mean values with their standard errors)

\begin{tabular}{|c|c|c|c|c|c|c|c|c|c|c|c|c|}
\hline \multirow[b]{2}{*}{ Items } & \multicolumn{3}{|c|}{ LPS-injected group } & \multicolumn{3}{|c|}{ Saline-injected group } & \multirow[b]{2}{*}{ SEM } & \multicolumn{5}{|c|}{$P$} \\
\hline & $\begin{array}{c}1.05 \% \\
\text { Arg }\end{array}$ & $\begin{array}{c}1.42 \% \\
\text { Arg }\end{array}$ & $\begin{array}{c}1.90 \% \\
\text { Arg }\end{array}$ & $\begin{array}{c}1.05 \% \\
\text { Arg }\end{array}$ & $\begin{array}{c}1.42 \% \\
\text { Arg }\end{array}$ & $\begin{array}{c}1.90 \% \\
\text { Arg }\end{array}$ & & LPS & $\operatorname{Arg}$ & $\begin{array}{c}\text { LPS } \times \\
\text { Arg }\end{array}$ & L† & Q† \\
\hline $\mathrm{BW} \ddagger(\mathrm{g}, 14 \mathrm{~d})$ & 303 & 366 & 366 & 294 & 369 & 371 & $14 \cdot 7$ & - & $<0.001$ & - & - & - \\
\hline BWG§ (g, 14-21 d) & 256 & 309 & 319 & 275 & 345 & 355 & $15 \cdot 7$ & $<0.001$ & 0.007 & 0.857 & $<0.001$ & 0.001 \\
\hline $\mathrm{FI}(\mathrm{g}, 14-21 \mathrm{~d})$ & 375 & 458 & 425 & 455 & 515 & 508 & 21.5 & $<0.001$ & $<0.001$ & 0.706 & 0.001 & $<0.001$ \\
\hline FCR§ $(14-21 d)$ & 1.48 & 1.49 & 1.38 & $1.66^{a, b}$ & $1.50^{\mathrm{a}, \mathrm{b}}$ & $1.45^{\mathrm{a}, \mathrm{b}}$ & 0.04 & $<0.001$ & 0.003 & 0.040 & - & - \\
\hline
\end{tabular}

L, linear; Q, quadratic; BW, body weight; BWG, body-weight gain; FI, feed intake; FCR, feed conversion ratio.

a,b Mean values within a row with unlike superscript letters have $\mathrm{L} L$ and $\mathrm{Q}$ dose response to $\operatorname{Arg}$ concentrations $(P<0.05)$

* LPS injection: chickens were injected with LPS (1 mg/kg of BW) four times at $48 \mathrm{~h}$ intervals from 14 to $20 \mathrm{~d}$; saline injection (control): chickens were injected with the same amount of sterile saline $(0.9 \%)$.

$\dagger \mathrm{L}$ and $\mathrm{Q}$ contrasts on the main effect means for Arg concentrations (averaged over LPS treatments).

$\ddagger$ Analysed by ANOVA.

$\S$ Analysed by covariance analysis using $14 \mathrm{~d}$ BW as the covariant. 
Table 5. Effect of graded supplementation of arginine (Arg) $(1.05,1.42$ or $1.90 \%)$ on the phagocytic activity of splenic heterophils and macrophages of broiler chickens on day 7 after continuous lipopolysaccharide (LPS) injection (Expt 1)*

(Mean values with their standard errors)

\begin{tabular}{|c|c|c|c|c|c|c|c|c|c|c|c|c|}
\hline \multirow[b]{2}{*}{ Items } & \multicolumn{3}{|c|}{ LPS-injected group } & \multicolumn{3}{|c|}{ Saline-injected group } & \multirow[b]{2}{*}{ SEM } & \multicolumn{5}{|c|}{$P$} \\
\hline & $\begin{array}{c}1.05 \% \\
\text { Arg }\end{array}$ & $\begin{array}{c}1.42 \% \\
\text { Arg }\end{array}$ & $\begin{array}{c}1.90 \% \\
\operatorname{Arg}\end{array}$ & $\begin{array}{l}1.05 \% \\
\operatorname{Arg}\end{array}$ & $\begin{array}{c}1.42 \% \\
\operatorname{Arg}\end{array}$ & $\begin{array}{c}1.90 \% \\
\text { Arg }\end{array}$ & & LPS & Arg & LPS $\times$ Arg & $\mathrm{L} \dagger$ & Q† \\
\hline $\begin{array}{l}\text { Phagocytosis by } \\
\text { heterophils (\%)‡ }\end{array}$ & 13.45 & $13 \cdot 41$ & $14 \cdot 14$ & $30 \cdot 46$ & $32 \cdot 26$ & 33.03 & $4 \cdot 10$ & $<0.001$ & 0.880 & 0.944 & 0.531 & 0.767 \\
\hline $\begin{array}{l}\text { Phagocytic intensity } \\
\text { of heterophils (MFI) }\end{array}$ & 1690 & 1749 & 1825 & 1929 & 1781 & 1899 & $37 \cdot 0$ & 0.390 & 0.833 & 0.797 & 0.742 & 0.833 \\
\hline $\begin{array}{l}\text { Phagocytosis by } \\
\text { macrophages (\%) }\end{array}$ & $6 \cdot 56$ & 9.00 & $6 \cdot 48$ & $9 \cdot 11$ & $9 \cdot 03$ & $10 \cdot 21$ & 0.62 & 0.035 & 0.622 & 0.240 & 0.320 & 0.556 \\
\hline $\begin{array}{l}\text { Phagocytic intensity } \\
\text { of macrophages (MFI) }\end{array}$ & 2689 & 2780 & 2745 & 2879 & 2562 & 2584 & $49 \cdot 4$ & 0.705 & 0.804 & 0.557 & 0.549 & 0.801 \\
\hline
\end{tabular}

$\mathrm{L}$, linear; Q, quadratic; MFI, mean fluorescence intensity.

* LPS injection: chickens were injected with LPS (1 mg/kg of BW) four times at $48 \mathrm{~h}$ intervals from 14 to $20 \mathrm{~d}$; saline injection (control): chickens were injected with the same amount of sterile saline $(0.9 \%)$.

$\dagger L$ and $Q$ contrasts on the main effect means for Arg concentrations (averaged over LPS treatments).

$\ddagger$ Percentage of phagocytic-active cells.

\section{Immune cell phenotypes}

The effect of dietary Arg concentration on splenocyte phenotypes is summarised in Table 6. Increasing dietary Arg concentrations linearly $(P<0.05)$ reduced the percentages of splenic Bu1 ${ }^{+}, \mathrm{CD}_{1} 1^{+}$and $\mathrm{CD} 14^{+}$cells (percentages of splenic lymphocytes), whereas no significant difference was found in the percentages of splenic $\mathrm{CD}^{+}$cells $(P>0.05)$. Compared with the control treatment, LPS injection significantly reduced $(P<0.05)$ the percentages of $\mathrm{Bu}^{+}$and $\mathrm{CD} 11^{+}$cells in the spleen and tended to reduce the percentage of $\mathrm{CD} 14^{+}$cells $(P<0 \cdot 10)$. No significant $(P>0 \cdot 05)$ difference was observed in the percentages of $\mathrm{CD}^{+}$cells. The percentage of total lymphocytes in the spleen (percentage of total splenocytes) was not influenced by either LPS injection or Arg supplementation $(P>0.05)$.

\section{Gene expression in the spleen and caecal tonsils}

LPS injection significantly $(P<0.05)$ increased the expression of the pro-inflammatory cytokines IL- $1 \beta$ in the spleen and IL-6 in the caecal tonsils. Dietary Arg supplementation linearly decreased $(P<0.05)$ the expression of IL-1 $\beta$ in the spleen; however, no significant $(P>0.05)$ effect was found on the expression of IL-6. LPS injection significantly $(P<0.05)$ reduced the expression of the anti-inflammatory cytokine IL-10 in the spleen, while increasing Arg concentrations linearly and quadratically $(P<0.05)$ decreased the expression of IL-10 in the caecal tonsils. LPS injection significantly increased the expression of TLR $4(P<0.05)$ in the spleen and tended to up-regulate the expression of TLR 4 in the caecal tonsils $(P=0.061)$, while dietary Arg supplementation linearly $(P<0.05)$ down-regulated the expression of TLR 4 in the spleen and caecal tonsils. In the caecal tonsils, dietary Arg supplementation linearly and quadratically $(P<0.05)$ decreased the expression of NF- $\mathrm{B}$; however, no significant $(P>0.05)$ effect was observed in the spleen. The expression of PPAR- $\gamma$ tended $(P=0.052)$ to be reduced by LPS injection in the caecal tonsils. Dietary Arg supplementation quadratically $(P<0.05)$ reduced the expression of PPAR- $\gamma$ in the spleen. There was a LPS $\times$ Arg interaction $(P<0 \cdot 05)$ for the expression of IL-1 $\beta$ in the caecal tonsils, wherein dietary Arg supplementation had no significant $(P>0.05)$ effect on the non-challenged chickens,

Table 6. Effect of graded supplementation of arginine (Arg) $(1.05,1.42$ or $1.90 \%)$ on the percentages of splenic leucocytes expressing cell-surface antigens for CD3, B cells (Bu-1), CD11 and CD14 of broiler chickens on day 7 after continuous lipopolysaccharide (LPS) injection* (Expt 1)

(Mean values with their standard errors)

\begin{tabular}{|c|c|c|c|c|c|c|c|c|c|c|c|c|}
\hline \multirow[b]{2}{*}{ Items } & \multicolumn{3}{|c|}{ LPS-injected group } & \multicolumn{3}{|c|}{ Saline-injected group } & \multirow[b]{2}{*}{ SEM } & \multicolumn{5}{|c|}{$P$} \\
\hline & $\begin{array}{c}1.05 \% \\
\text { Arg }\end{array}$ & $\begin{array}{c}1.42 \% \\
\text { Arg }\end{array}$ & $\begin{array}{c}1.90 \% \\
\text { Arg }\end{array}$ & $\begin{array}{c}1.05 \% \\
\text { Arg }\end{array}$ & $\begin{array}{c}1.42 \% \\
\text { Arg }\end{array}$ & $\begin{array}{c}1.90 \% \\
\text { Arg }\end{array}$ & & LPS & Arg & LPS $\times$ Arg & L† & Q† \\
\hline $\mathrm{CD}^{+}(\%) \ddagger$ & $16 \cdot 19$ & 16.53 & 21.40 & $19 \cdot 51$ & $21 \cdot 16$ & $20 \cdot 60$ & 0.95 & 0.126 & 0.228 & 0.334 & 0.090 & 0.195 \\
\hline $\mathrm{Bu}-1^{+}(\%) \ddagger$ & 39.73 & 37.09 & $30 \cdot 87$ & $49 \cdot 14$ & $44 \cdot 73$ & 43.54 & $2 \cdot 62$ & 0.003 & 0.081 & 0.712 & 0.049 & 0.152 \\
\hline $\mathrm{CD} 11^{+}(\%) \ddagger$ & $10 \cdot 01$ & 6.60 & $5 \cdot 34$ & $12 \cdot 65$ & 13.45 & $9 \cdot 22$ & 1.31 & 0.004 & 0.093 & 0.497 & 0.040 & 0.116 \\
\hline $\mathrm{CD}_{14}{ }^{+}(\%) \ddagger$ & 2.48 & $2 \cdot 16$ & 1.76 & 2.93 & 1.98 & 2.66 & 0.18 & 0.098 & 0.075 & 0.161 & 0.023 & 0.078 \\
\hline Lymphocyte (\%)§ & 31.81 & $34 \cdot 22$ & 33.05 & 33.44 & 33.08 & 33.80 & 0.34 & 0.471 & 0.573 & 0.380 & 0.503 & 0.562 \\
\hline
\end{tabular}

L, linear; Q, quadratic.

* LPS injection: chickens were injected with LPS ( $1 \mathrm{mg} / \mathrm{kg}$ of BW) four times at $48 \mathrm{~h}$ intervals from 14 to $20 \mathrm{~d}$; saline injection (control): chickens were injected with the same amount of sterile saline $(0.9 \%)$.

$\dagger \mathrm{L}$ and $\mathrm{Q}$ contrasts on the main effect means for Arg concentrations (averaged over LPS treatments).

$\ddagger$ Based on gated lymphocytes.

$\S$ Based on total splenocytes. 
whereas it linearly and quadratically $(P<0.05)$ reduced the expression of IL-1 $\beta$ in the caecal tonsils of the LPS-challenged chickens (Table 7).

\section{Expt 2}

With the increase in dietary Arg concentrations, the percentage of circulating $\mathrm{B}$ cells (percentage of circulating lymphocytes) decreased linearly $(P<0 \cdot 01)$, quadratically $(P<0 \cdot 01)$ and cubically $(P<0.05)$. The percentage of total circulating lymphocytes (percentage of isolated PBMC) was not influenced by the dietary Arg concentration ( $P>0.05$; Fig. 1$)$.

\section{Discussion}

Animals that are raised in an environment in which they are exposed to frequent microbial challenges grow at a slower growth rate and have lower nutrient utilisation, which cause a tremendous loss to poultry production ${ }^{(28)}$. Studies in mammals and birds have demonstrated that Arg is an important immune-modulatory nutrient, wherein dietary Arg supplementation could enhance both innate and adaptive immune functions of animals ${ }^{(2,29)}$. Arg supplementation has been used to alleviate inflammatory response in mammalian models ${ }^{(12)}$. Although the immune system of birds, which is different from that of mammals, is well characterised, the regulatory function of Arg in the inflammatory response of chickens is still unknown. To evaluate whether Arg supplementation alleviates the inflammatory response in broiler chickens, a model for inducing inflammation in broilers by injecting $E$. coli LPS was used.

The suppression of the growth performance of animals reared in unsanitary environments is thought to be a result of excessive immune defence response, such as inflammation, which is marked by reduced FI and muscle protein accretion and wasted energy and protein for defence protein synthesis (e.g. acute-phase proteins) ${ }^{(28,30)}$. We employed a previously described inflammatory model wherein repeated injections of LPS resulted in a significant reduction in weight gain and $\mathrm{FI}^{(28,31)}$, which is in agreement with the results of the present study. One may question whether LPS-induced reductions in performance are primarily a result of reductions in FI or excessive inflammatory response. A previous report from our laboratory $^{(32)}$ has demonstrated that compared with pair-feeding (the same amount of feed is fed), LPS injection significantly reduces BWG and increases the FCR of chickens (14-21d), which provides evidence that activation of the inflammatory system of chickens is costly in terms of growth beyond that of only reducing FI. In the present study, LPS injection increased the expression of inflammatory cytokines IL-1 $\beta$, IL- 6 and TLR4, which suppressed growth processes by directing nutrients away from body protein accretion to support the immune response. Thus, if Arg supplementation could alleviate the inflammatory response of chickens, it could be used as an important component for designing immune-enhancing diets to diminish the economic loss caused by infection, which has been considered as an effective nutritional strategy to reduce infection rates and post-infection recovery ${ }^{(33,34)}$.

Phagocytosis is an innate immune reaction for the clearance of bacterial infections of animals, which plays an indispensable role in the defence against various infections ${ }^{(35)}$. In chickens, heterophils are key components of the innate immune system that play a role similar to that of neutrophils in mammals ${ }^{(36)}$. Heterophils are highly phagocytic and have a broad spectrum of antimicrobial activities ${ }^{(37)}$. A previous study has reported that dietary Arg supplementation increases the proportion of circulating heterophils in chickens ${ }^{(38)}$, but it

Table 7. Effect of graded supplementation of arginine (Arg) $(1.05,1.42$ or $1.90 \%)$ on the relative mRNA expression of pro/anti-inflammatory cytokine and inflammatory regulation genes in the spleen and caecal tonsils of broiler chickens on day 7 after continuous lipopolysaccharide (LPS) injection* (Expt 1)

(Mean values with their standard errors)

\begin{tabular}{|c|c|c|c|c|c|c|c|c|c|c|c|c|}
\hline \multirow[b]{2}{*}{ Items } & \multicolumn{3}{|c|}{ LPS-injected group } & \multicolumn{3}{|c|}{ Saline-injected group } & \multirow[b]{2}{*}{ SEM } & \multicolumn{5}{|c|}{$P$} \\
\hline & $\begin{array}{c}1.05 \% \\
\text { Arg }\end{array}$ & $\begin{array}{c}1.42 \% \\
\operatorname{Arg}\end{array}$ & $\begin{array}{c}1.90 \% \\
\text { Arg }\end{array}$ & $\begin{array}{c}1.05 \% \\
\text { Arg }\end{array}$ & $\begin{array}{c}1.42 \% \\
\text { Arg }\end{array}$ & $\begin{array}{c}1.90 \% \\
\text { Arg }\end{array}$ & & LPS & Arg & LPS $\times$ Arg & $\mathrm{L} \dagger$ & Q† \\
\hline \multicolumn{13}{|l|}{ Spleen } \\
\hline$I L-1 \beta$ & 0.34 & 0.24 & 0.20 & 0.20 & 0.20 & 0.11 & 0.03 & 0.035 & 0.076 & 0.627 & 0.030 & 0.092 \\
\hline$I L-6$ & 0.06 & 0.03 & 0.02 & 0.02 & 0.02 & 0.01 & 0.01 & 0.126 & 0.356 & 0.530 & 0.119 & 0.284 \\
\hline$I L-10$ & 0.74 & 0.82 & 0.55 & 1.01 & 0.98 & 0.78 & 0.07 & 0.018 & 0.109 & 0.722 & 0.100 & 0.170 \\
\hline TLR4 & 4.54 & 3.96 & 1.51 & 2.04 & 1.48 & 1.25 & 0.58 & 0.033 & 0.081 & 0.212 & 0.025 & 0.078 \\
\hline$N F-\kappa B$ & 1.56 & 1.58 & 0.81 & 1.33 & $1 \cdot 15$ & $1 \cdot 24$ & 0.12 & 0.614 & 0.107 & 0.121 & 0.070 & 0.122 \\
\hline$P P A R-\gamma$ & 1.25 & 1.45 & 0.85 & 1.37 & 1.34 & 0.98 & 0.10 & 0.778 & 0.038 & 0.755 & 0.056 & 0.032 \\
\hline \multicolumn{13}{|c|}{ Caecal tonsils } \\
\hline$I L-1 \beta$ & $2 \cdot 41^{a, b}$ & $1.54^{\mathrm{a}, \mathrm{b}}$ & $1 \cdot 00^{a, b}$ & 0.71 & 0.85 & 0.60 & 0.28 & $<0.001$ & 0.002 & 0.005 & - & - \\
\hline IL-6 & 1.38 & 0.99 & 0.37 & 0.28 & 0.51 & 0.36 & 0.18 & 0.039 & 0.351 & 0.323 & 0.257 & 0.494 \\
\hline$I L-10$ & $1 \cdot 19$ & 0.88 & 0.87 & $2 \cdot 05$ & $1 \cdot 72$ & 0.81 & 0.21 & 0.214 & 0.009 & 0.388 & 0.004 & 0.016 \\
\hline$T L R 4$ & 1.41 & 0.98 & 0.83 & 0.91 & 0.93 & 0.79 & 0.09 & 0.061 & 0.054 & 0.250 & 0.032 & 0.096 \\
\hline$N F-\kappa B$ & 1.45 & 1.02 & 0.96 & $1 \cdot 23$ & $1 \cdot 32$ & 0.91 & 0.09 & 0.955 & 0.021 & 0.155 & 0.004 & 0.016 \\
\hline$P P A R-\gamma$ & 0.92 & 1.03 & 1.05 & 1.43 & 1.49 & $1 \cdot 18$ & 0.09 & 0.052 & 0.817 & 0.668 & 0.866 & 0.820 \\
\hline
\end{tabular}

L, linear; Q, quadratic; TLR4, Toll-like receptor 4.

a,b Mean values within the LPS- or saline-injected groups have a linear and quadratic dose response to Arg concentrations $(P<0 \cdot 05)$.

* LPS injection: chickens were injected with LPS (1 mg/kg of BW) four times at $48 \mathrm{~h}$ intervals from 14 to $20 \mathrm{~d}$; saline injection (control): chickens were injected with the same amount of sterile saline $(0.9 \%)$.

$\dagger L$ and $Q$ contrasts on the main effect means for Arg concentrations (averaged over LPS treatments). 

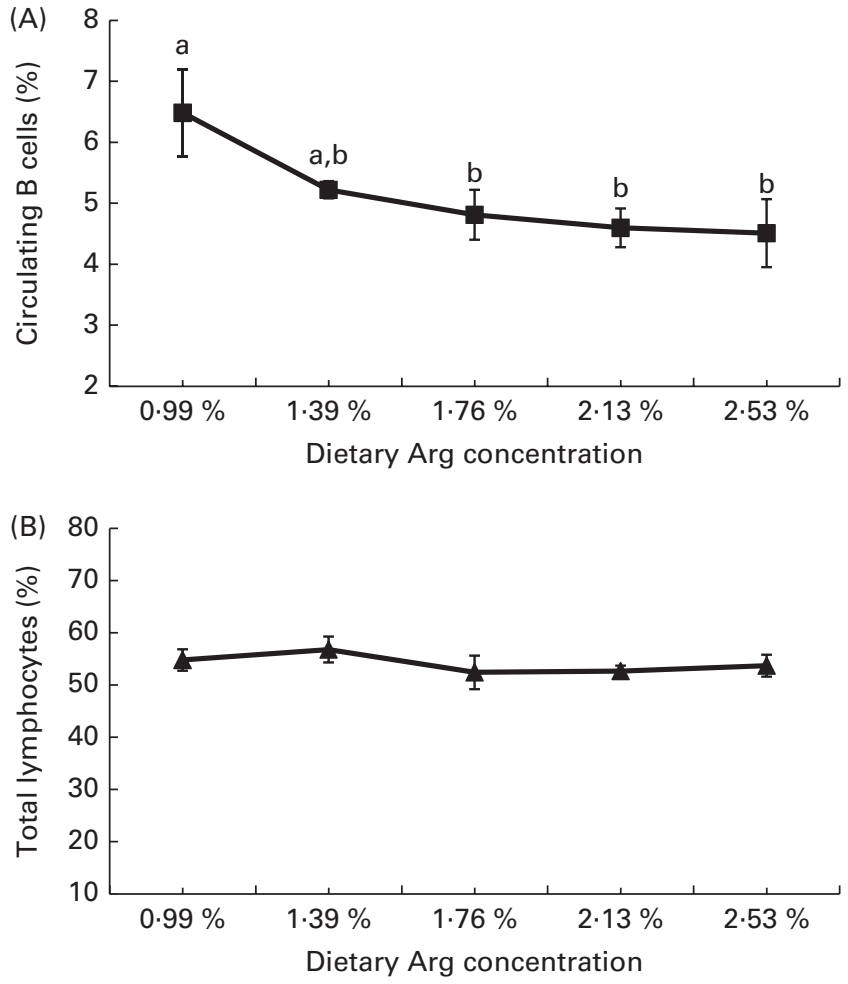

Fig. 1. Effect of dietary L-arginine (Arg) concentration on (A) the percentage of circulating $B$ cells (based on gated total lymphocytes) and (B) the percentage of gated total lymphocytes (based on isolated peripheral blood mononuclear cells) (21d, Expt 2). Values are means of ten individual chickens, with their standard errors represented by vertical bars. ${ }^{\mathrm{a}, \mathrm{b}}$ Mean values ( $\boldsymbol{\square}$ ) with unlike letters were significantly different $(P \leq 0.05)$. The percentage of circulating $\mathrm{B}$ cells decreased linearly $(P=0.002)$, quadratically $(P=0.002)$ and cubically $(P=0.022)$ with increasing dietary Arg concentrations $(P<0.01)$. No effect was observed on the percentage of gated total lymphocytes $(P>0.05)$. (B) Linear $(P=0.171)$, quadratic $(P=0.315)$ and cubic $(P=0.253)$.

failed to enhance the phagocytic activity of heterophils in the present study. Macrophages are a key arm of the innate immune defence system in intracellular bacterial killing ${ }^{(39)}$. The antimicrobial activities of macrophages are due to the generation of reactive oxygen species and reactive $\mathrm{N}$ species, such as $\mathrm{H}_{2} \mathrm{O}_{2}$ and $\mathrm{NO}$, which are important metabolites of $\operatorname{Arg}^{(2)}$. An in vitro study in channel catfish has suggested that supplementation of Arg to cell-culture media enhances the phagocytic activity of head kidney macrophages ${ }^{(40)}$, but no significant influence was observed in the present study. Central to inflammation is the recruitment of leucocytes to the site of infection, which is characterised by the migration of heterophils and macrophages from blood and spleen to the site of infection ${ }^{(41)}$. Therefore, LPS injection induced the migration of leucocytes from the spleen to the site of injection, which suppressed the phagocytic activity of heterophils and macrophages in the spleen.

It is well known that Arg plays an important role in the development of $\mathrm{T}$ cells ${ }^{(42)}$, as Arg deprivation arrests $\mathrm{T}$ cells in the $G_{0}-G_{1}$ phase of the cell cycle ${ }^{(43)}$, and Arg deficiency can have an unambiguous effect on early B-cell development ${ }^{(44)}$. In the present study, no significant effect of Arg deficiency was observed on the percentage of $\mathrm{CD}^{+} \mathrm{T}$ cells, while increasing dietary Arg concentrations significantly reduced the percentages of both splenic and circulating $\mathrm{B}$ cells $(P<0 \cdot 05)$. Previous studies have reported that $\mathrm{H}_{2} \mathrm{O}_{2}$ can cause the apoptosis of macrophages by mitochondrial membrane depolarisation $^{(45)}$. In our previous study (J Tan, Y Guo, TJ Applegate and E Du, unpublished results), dietary Arg supplementation quadratically $(P<0.05)$ increased in vitro macrophage $\mathrm{H}_{2} \mathrm{O}_{2}$ production. Thus, the decrease in the proportion of $\mathrm{B}$ cells may be associated with the increasing production of $\mathrm{H}_{2} \mathrm{O}_{2}$, which could be synthesised by Arg through a NO synthase-2-depedent metabolic pathway ${ }^{(2)}$. It is well known that immune-modulating nutrients can be helpful as well as harmful if not utilised in moderation ${ }^{(46)}$, such as n-3 PUFA, which could be used to reduce the adverse effects of infectious bursal disease ${ }^{(47)}$ and improve cellular immunity ${ }^{(48)}$ of chickens, while it increases the incidence of Marek's disease $^{(49)}$. Thus, further research should be conducted to gain a better understanding of the optimal immune response for dietary Arg supplementation to direct the immune system in an optimal direction.

Cytokines are small, non-structural proteins with molecular weights ranging from 8 to $40000 \mathrm{Da}$. Pro-inflammatory cytokines such as IL-1 $\beta$, IL- 6 and TNF- $\alpha$ promote inflammation, whereas anti-inflammatory cytokines such as IL-4, IL-10 and IL-13 suppress inflammation ${ }^{(50)}$. LPS injection has been used to trigger pro-inflammatory cytokine response in chickens ${ }^{(15)}$, which was considered to be a result of TLR 4 activation ${ }^{(14)}$ When expressed in excess, pro-inflammatory cytokines may cause fever, inflammation and tissue destruction ${ }^{(51)}$. In the present study, the overexpression of IL- $1 \beta$ in the spleen and caecal tonsils was alleviated by dietary Arg supplementation, indicating that Arg supplementation may have a beneficial effect on the attenuation of the inflammatory response induced by LPS injection.

IL-10 is a critical anti-inflammatory cytokine secreted by activated macrophages that serves as a feedback response of inflammation to prevent the excessive expression of proinflammatory cytokines. T helper (Th) 2 cytokines, such as IL-10 and IL-4, could activate arginase-1 in macrophages ${ }^{(1)}$, which converts Arg into ornithine, and ornithine can be decarboxylated by ornithine decarboxylase to produce putrescine and further converted into polyamines (spermidine and spermine). Polyamines have been reported to be important inhibitory substances for the LPS-induced expression of proinflammatory cytokines ${ }^{(52)}$. In the present study, LPS injection decreased the expression of IL-10, which is in agreement with the findings of a previous study ${ }^{(53)}$. However, dietary Arg supplementation failed to enhance the expression of IL-10. PPAR are members of the nuclear hormone receptor family. PPAR ligands, in particular, PPAR- $\gamma$ ligands, could inhibit inflammatory response and negatively regulate pro-inflammatory transcription factor signalling pathways in inflammatory cells ${ }^{(54)}$. Nutritional dietary strategies have been described to enhance the expression of PPAR- $\gamma$, which exerts a beneficial effect on the alleviation of the inflammatory response induced by LPS injection ${ }^{(55)}$. However, dietary Arg supplementation failed to enhance the expression of PPAR- $\gamma$. Thus, Arg does not modulate the inflammatory response through anti-inflammatory cytokines and the PPAR- $\gamma$ pathway. 
Chicken CD14 is $34 \%$ homologous to human orthologues at the protein level, and they share several structural features such as conserved leucine-rich repeats and conserved cysteines $^{(56)}$. Mammalian CD14 is expressed as a glycosylphosphatidylinositol (GPI) anchored cell-surface protein that can be released as a soluble serum protein $(\mathrm{sCD} 14)^{(57)}$. In the absence of chicken serum, LPS induced the up-regulation of pro-inflammatory cytokine and chemokine gene expression in chicken heterophils, indicating that LPS can be directly recognised by CD14 or TLR4, while the presence of chicken serum or mouse LBP dramatically enhanced the activation of heterophils, suggesting that a functional protein similar to mammalian LBP may exists in chicken serum ${ }^{(58)}$. Chicken CD14 plays an unclear role in LPS sensing, while chicken CD14 is essential for the activation of LPS-induced pro-inflammatory cytokine response ${ }^{(59)}$. Panaro et al. ${ }^{(60)}$ reported that the activation of chicken embryo cardiomyocyte inflammation by LPS requires the engagement of both TLR 4 and CD14, since anti-CD14 pretreatment of cardiomyocytes prevents the production of pro-inflammatory cytokines. A similar finding has been reported for chicken macrophages, with the administration of either anti-CD14 or anti-TLR4 antibodies completely blocking LPS-mediated inducible NO synthase (iNOS) activation, suggesting that both CD14 and TLR4 are required for LPS-mediated iNOS activation ${ }^{(61)}$. The inhibition of CD14, such as with an anti-CD14 antibody, has been used as a therapeutic approach to protect primates from LPS-induced shock due to overexpression of inflammatory cytokines ${ }^{(62)}$. In the present study, increasing dietary Arg concentrations linearly reduced the percentage of $\mathrm{CD}_{1} 4^{+}$cells in the spleen. Therefore, Arg supplementation could be suggested as a potential nutritional approach for the mediation of a hyperinflammatory response. Since the exact role that chicken CD14 plays in inflammatory response is still unclear, further studies are needed to get the whole picture.

Chicken TLR 4 is about $43 \%$ homologous to human orthologues at the protein level ${ }^{(59)}$. Chicken sense LPS via the TLR4 and myeloid differentiation protein- 2 complex and further activate the NF- $\mathrm{BB}$ inflammatory cascade ${ }^{(14,63)}$. Compared with mammalian species, chicken lack the myeloid differentiation factor 88 (MyD88)-independent signalling pathway in which the downstream production of interferon- $\beta$ occurs in mammals ${ }^{(14)}$. Mammalian TLR4/myeloid differentiation protein-2 complex depends on two different intracellular signalling routes for NF- $\mathrm{B}$ activation: the MyD88/Toll-IL 1 receptor domain-containing adaptor protein (TIRAP) and TRAM/TRIF (TRIF-related adaptor molecule/Toll-IL 1 receptor domain-containing adaptor inducing interferon) pathways ${ }^{(64)}$. As chickens lack an orthologue of TRAM that bridges TLR 4 and TRIF, chicken TLR4 signals only by the MyD88/TIRAPdependent pathway ${ }^{(65)}$. The result reported herein showed that LPS injection increased the expression of TLR 4 mRNA in the spleen and caecal tonsils and activated the pro-inflammatory cytokine response. Interestingly, dietary Arg supplementation suppressed the expression of TLR 4 mRNA linearly. Thus, the suppression of the TLR4 pathway could be one of the mechanisms by which Arg alleviates inflammatory response. In subclinical conditions, the local inflammatory response recruits other phagocytic or non-phagocytic lymphocytes to eliminate foreign pathogens, which is very important for host defence. Therefore, under these conditions, the suppression of the TLR 4 pathway and CD $14^{+}$cell percentage could be a potential negative effect.

In cells (e.g. macrophages and myeloid cells), Arg is mainly metabolised by iNOS or by arginase- 1 to synthesise NO and polyamines, respectively ${ }^{(1)}$. iNOS and arginase- 1 are stimulated by Th1 and Th2 cytokines, respectively ${ }^{(2)}$. Dietary Arg supplementation failed to enhance the expression of Th2 cytokines (IL-2 and IL-10) in the present study; thus, Arg may not exert its inflammation-modulatory effects through the arginase-1 pathway. Previous work has shown that oral administration of Arg attenuates LPS-induced lung chemokine production in mice ${ }^{(4)}$. This effect is dependent on $\mathrm{NO}$ and is mediated by the stabilisation of inhibitory $\kappa \mathrm{B}-\alpha$ concentrations. Studies in mice have also shown that Arg supplementation could alleviate the inflammatory response in dextran sulphate sodium colitis, while this benefit has been found to be eliminated when tested in the NNOS $^{-/-}$mice $^{(12)}$. Furthermore, a study in chickens has shown that dietary Arg supplementation could increase circulating NO production ${ }^{(66)}$; thus, we conclude that the beneficial effect of Arg on the alleviation of inflammatory response depends on NO through the iNOS pathway. Regretfully, in the present study, no direct evidence was obtained to prove whether Arg has a direct effect or acts through $\mathrm{NO}$ on the percentages of $\mathrm{CD} 11^{+}$and $\mathrm{CD} 14^{+}$cells and expression of TLR4, thus, requiring further studies.

In summary, the present study demonstrates that dietary Arg supplementation alleviated systemic inflammation of LPSchallenged chickens. It is possible that the ability of Arg to alleviate systemic inflammation is associated with the reduction in the expression of pro-inflammatory cytokines via the suppression of the TLR 4 pathway and percentage of $\mathrm{CD} 14^{+}$cells (percentage of splenic lymphocytes). The results obtained in the present study clarified the molecular events by which Arg alleviated the systemic inflammatory response caused by LPS injection. Furthermore, excessive dietary Arg supplementation suppressed the percentages of both splenic $(1.90 \%)$ and peripheral blood B cells (1.76\%) (percentage of splenic and circulating lymphocytes).

\section{Acknowledgements}

The authors thank Bertrand Grenier, Sunday A. Adedokun, Qian Zhang, Xi Chen and Kolapo Ajuwon for their help with the experiments.

The present study was supported by a grant from the China Agriculture Research System (CARS-42-G13) and China Scholarship Council. The funders (China Agricultural University and China Scholarship Council) had no role in the design or analysis of the study and in the writing of this article.

Mention of trade names or commercial products in this article is solely for the purpose of providing specific information and does not imply recommendation or endorsement by the US Department of Agriculture.

USDA is an equal-opportunity employer. 
Data reported herein were partially presented at the 2013 PSA Annual Meeting, San Diego, CA (July 2013).

The authors' contributions are as follows: J. T. conducted the animal trial, carried out the sample analyses and wrote the manuscript; S. L. assisted with all the data analyses; T. J. A. contributed to the study design, conduct of the study and preparation of the manuscript; Y. G. and S. D. E. contributed to the experimental design and manuscript preparation.

There is no conflict of interest to be disclosed.

\section{References}

1. Popovic PJ, Zeh HJ \& Ochoa JB (2007) Arginine and immunity. J Nutr 137, 1681S-1686S.

2. Bronte V \& Zanovello P (2005) Regulation of immune responses by L-arginine metabolism. Nat Rev Immunol $\mathbf{5}$, 641-654.

3. Luiking YC, Poeze M, Ramsay G, et al. (2009) Reduced citrulline production in sepsis is related to diminished de novo arginine and nitric oxide production. Am J Clin Nutr 89, 142-152.

4. Calkins CM, Bensard DD, Heimbach JK, et al. (2001) L-Arginine attenuates lipopolysaccharide-induced lung chemokine production. Am J Physiol Lung Cell Mol Physiol 280, L400-L 408 .

5. Shi HP, Efron DT, Most D, et al. (2000) Supplemental dietary arginine enhances wound healing in normal but not inducible nitric oxide synthase knockout mice. Surgery 128, 374-378.

6. Tayade C, Jaiswal T, Mishra S, et al. (2006) L-Arginine stimulates immune response in chickens immunized with intermediate plus strain of infectious bursal disease vaccine. Vaccine 24, 552-560.

7. NRC (1994) Nutrient Requirements of Poultry, 9th ed. Washington, DC: National Academy Press.

8. Jahanian R (2009) Immunological responses as affected by dietary protein and arginine concentrations in starting broiler chicks. Poult Sci 88, 1818-1824.

9. Roura E, Homedes J \& Klasing KC (1992) Prevention of immunologic stress contributes to the growth-permitting ability of dietary antibiotics in chicks. J Nutr 122, 2383-2390.

10. Munir K, Muneer MA, Masaoud E, et al. (2009) Dietary arginine stimulates humoral and cell-mediated immunity in chickens vaccinated and challenged against hydropericardium syndrome virus. Poult Sci 88, 1629-1638.

11. Han J, Liu Y, Fan W, et al. (2009) Dietary L-arginine supplementation alleviates immunosuppression induced by cyclophosphamide in weaned pigs. Amino Acids 37, 643-651.

12. Coburn LA, Gong X, Singh K, et al. (2012) L-Arginine supplementation improves responses to injury and inflammation in dextran sulfate sodium colitis. PLOS ONE 7, e33546.

13. Zhang M, Nii T, Isobe N, et al. (2012) Expression of Toll-like receptors and effects of lipopolysaccharide on the expression of proinflammatory cytokines and chemokine in the testis and epididymis of roosters. Poult Sci 91, 1997-2003.

14. Keestra AM \& Putten JPM (2008) Unique properties of the chicken TLR4/MD-2 complex: selective lipopolysaccharide activation of the MyD88-dependent pathway. J Immunol 181, 4354-4362.

15. Munyaka PM, Tactacan G, Jing M, et al. (2012) Immunomodulation in young laying hens by dietary folic acid and acute immune responses after challenge with Escherichia coli lipopolysaccharide. Poult Sci 91, 2454-2463.

16. Lu YC, Yeh WC \& Ohashi PS (2008) LPS/TLR4 signal transduction pathway. Cytokine 42, 145-151.

17. Beutler B (2000) TLR4: central component of the sole mammalian LPS sensor. Curr Opin Immunol 12, 20-26.

18. Zhang X, Zhong X, Zhou Y, et al. (2010) Dietary RRR- $\alpha$-tocopherol succinate attenuates lipopolysaccharide-induced inflammatory cytokines secretion in broiler chicks. $\mathrm{Br} J$ Nutr 104, 1796-1805.

19. Baker RG, Hayden MS \& Ghosh S (2011) NF-кB, inflammation, and metabolic disease. Cell Metab 13, 11-22.

20. Tan B, Yin Y, Kong X, et al. (2010) L-Arginine stimulates proliferation and prevents endotoxin-induced death of intestinal cells. Amino Acids 38, 1227-1235.

21. AOAC (2000) Official Methods of Analysis, 17th ed. Arlington, VA: AOAC

22. Park IJ, Cha SY, Kang M, et al. (2013) Immunomodulatory effect of a proanthocyanidin-rich extract from Pinus radiata bark by dosing period in chickens. Poult Sci 92, 352-357.

23. Long FY, Guo YM, Wang Z, et al. (2011) Conjugated linoleic acids alleviate infectious bursal disease virus-induced immunosuppression in broiler chickens. Poult Sci 90, 1926-1933.

24. Watson JV (2004) Introduction to Flow Cytometry Cambridge, UK: Cambridge University Press.

25. Dil N \& Qureshi MA (2002) Differential expression of inducible nitric oxide synthase is associated with differential Toll-like receptor 4 expression in chicken macrophages from different genetic backgrounds. Vet Immunol Immunop 84, 191-207.

26. Simms D, Cizdziel PE \& Chomczynski P (1993) TRIzol: a new reagent for optimal single-step isolation of RNA. Focus $\mathbf{1 5}$, $532-535$.

27. Livak KJ \& Schmittgen TD (2001) Analysis of relative gene expression data using real-time quantitative PCR and the $2^{-\Delta \Delta \mathrm{C}_{\mathrm{t}}}$ method. Methods 25, 402-408.

28. Klasing KC \& Barnes DM (1988) Decreased amino acid requirements of growing chicks due to immunologic stress. J Nutr 118, 1158-1164.

29. Tan B, Li XG, Kong X, et al. (2009) Dietary L-arginine supplementation enhances the immune status in early-weaned piglets. Amino Acids 37, 323-331.

30. Cook M (2010) A review of science leading to host-targeted antibody strategies for preventing growth depression due to microbial colonization. J Anim Sci 89, 1981-1990.

31. Webel DM, Johnson RW \& Baker DH (1998) Lipopolysaccharide-induced reductions in food intake do not decrease the efficiency of lysine and threonine utilization for protein accretion in chickens. J Nutr 128, 1760-1766.

32. Jiang Z, Schatzmayr G, Mohnl M, et al. (2010) Net effect of an acute phase response partial alleviation with probiotic supplementation. Poult Sci 89, 28-33.

33. Bansal V, Syres KM, Makarenkova V, et al. (2005) Interactions between fatty acids and arginine metabolism: implications for the design of immune-enhancing diets JPEN 29, S75-S80.

34. Ochoa JB, Makarenkova V \& Bansal V (2004) A rational use of immune enhancing diets: when should we use dietary arginine supplementation? Nutr Clin Pract 19, 216-225.

35. Seifert S, Fritz C, Carlini N, et al. (2011) Modulation of innate and adaptive immunity by the probiotic Bifidobacterium longum PCB133 in turkeys. Poult Sci 90, 2275-2280.

36. Chuammitri P, Redmond SB, Kimura K, et al. (2011) Heterophil functional responses to dietary immunomodulators vary 
in genetically distinct chicken lines. Vet Immunol Immunop 142, 219-227.

37. Harmon B (1998) Avian heterophils in inflammation and disease resistance. Poult Sci 77, 972-977.

38. Lee J, Austic R, Naqi S, et al. (2002) Dietary arginine intake alters avian leukocyte population distribution during infectious bronchitis challenge. Poult Sci 81, 793-798.

39. Ibuki M, Kovacs-Nolan J, Fukui K, et al. (2011) $\beta$ 1-4 Mannobiose enhances Salmonella-killing activity and activates innate immune responses in chicken macrophages. Vet Immunol Immunop 139, 289-295.

40. Pohlenz C, Buentello A, Mwangi W, et al. (2012) Arginine and glutamine supplementation to culture media improves the performance of various channel catfish immune cells. Fish Shellfish Immun 32, 762-768.

41. Gong Y, Hart E, Shchurin A, et al. (2008) Inflammatory macrophage migration requires MMP-9 activation by plasminogen in mice. J Clin Invest 118, 3012-3024.

42. Zea AH, Rodriguez PC, Culotta KS, et al. (2004) L-Arginine modulates $\mathrm{CD} 3 \zeta$ expression and $\mathrm{T}$ cell function in activated human T lymphocytes. Cell immunol 232, 21-31.

43. Rodriguez PC, Hernandez CP, Morrow K, et al. (2010) L-Arginine deprivation regulates cyclin $\mathrm{d} 3$ mRNA stability in human $\mathrm{T}$ cells by controlling HuR expression. J Immunol 185, 5198-5204.

44. Jonge WJ, Kwikkers KL, Velde AA, et al. (2002) Arginine deficiency affects early B cell maturation and lymphoid organ development in transgenic mice. J Clin Invest 110, 1539-1548.

45. Chaturvedi R, Cheng Y, Asim M, et al. (2004) Induction of polyamine oxidase 1 by Helicobacter pylori causes macrophage apoptosis by hydrogen peroxide release and mitochondrial membrane depolarization. J Biol Chem 279, 40161-40173

46. Klasing K (2007) Nutrition and the immune system. Br Poult Sci 48, 525-537.

47. Maroufyan E, Kasim A, Ebrahimi M, et al. (2012) Dietary methionine and $n-6 / n-3$ polyunsaturated fatty acid ratio reduce adverse effects of infectious bursal disease in broilers. Poult Sci 91, 2173-2182.

48. Wang MZ, Ding LY, Wang JF, et al. (2011) Effects of $n-6: n-3$ polyunsaturated fatty acid ratio on heterophil:lymphocyte ratio and $\mathrm{T}$ lymphocyte subsets in the peripheral blood of the Yangzhou gosling. Poult Sci 90, 824-829.

49. Klasing K \& Korver D (1999) The role of diet in modulating the immune response of broilers: the example of PUFAs. Recent Adv Anim Nutr Aust 12, 1-6.

50. Opal SM \& DePalo VA (2000) Anti-inflammatory cytokines. Chest 117, 1162-1172.

51. Dinarello CA (2000) Proinflammatory cytokines. Chest 118 503-508.

52. Bossche J, Lamers WH, Koehler ES, et al. (2012) Pivotal advance: arginase-1-independent polyamine production stimulates the expression of IL-4-induced alternatively activated macrophage markers while inhibiting LPS-induced expression of inflammatory genes. J Leukocyte Biol 91, 685-699.

53. Shanmugasundaram R \& Selvaraj RK (2012) In vivo lipopolysaccharide injection alters $\mathrm{CD}^{+} \mathrm{CD} 25^{+}$cell properties in chickens. J Anim Sci 90, 2498-2504.

54. Moraes LA, Piqueras L \& Bishop-Bailey D (2006) Peroxisome proliferator-activated receptors and inflammation. Pharmacol Therapeut 110, 371-385.

55. Zhang HJ, Guo YM, Yang Y, et al. (2006) Dietary conjugated linoleic acid enhances spleen PPAR- $\gamma$ mRNA expression in broiler chicks. Br Poult Sci 47, 726-733.

56. Wu Z, Rothwell L, Hu T, et al. (2009) Chicken CD14, unlike mammalian CD14, is transmembrane rather than GPIanchored. Dev Comp Immunol 33, 97-104.

57. Schutt C (1999) CD14. Int J Biochem Cell B 31, 545-549.

58. Kogut M, He H \& Kaiser P (2005) Lipopolysaccharide binding protein/CD14/TLR4-dependent recognition of Salmonella LPS induces the functional activation of chicken heterophils and up-regulation of pro-inflammatory cytokine and chemokine gene expression in these cells. Anim Biotechnol 16, 165-181.

59. Brownlie R \& Allan B (2011) Avian Toll-like receptors. Cell Tissue Res 343, 121-130.

60. Panaro MA, Cianciulli A, Gagliardi N, et al. (2008) CD14 major role during lipopolysaccharide-induced inflammation in chick embryo cardiomyocytes. FEMS Immunol Med Microbiol 53, 35-45.

61. Dil N \& Qureshi MA (2002) Involvement of lipopolysaccharide related receptors and nuclear factor $\kappa \mathrm{B}$ in differential expression of inducible nitric oxide synthase in chicken macrophages from different genetic backgrounds. Vet Immunol Immunop 88, 149-161.

62. Leturcq D, Moriarty A, Talbott G, et al. (1996) Antibodies against CD14 protect primates from endotoxin-induced shock. J Clin Invest 98, 1533.

63. Zoete MR, Keestra AM, Roszczenko P, et al. (2010) Activation of human and chicken Toll-like receptors by Campylobacter spp. Infect Immun 78, 1229-1238.

64. O'Neill LAJ \& Bowie AG (2007) The family of five: TIRdomain-containing adaptors in Toll-like receptor signalling. Nat Rev Immunol 7, 353-364.

65. Keestra AM, Zoete MR, Bouwman LI, et al. (2013) Unique features of chicken Toll-like receptors. Dev Comp Immunol 41, 316-323.

66. Khajali F, Tahmasebi M, Hassanpour H, et al. (2011) Effects of supplementation of canola meal-based diets with arginine on performance, plasma nitric oxide, and carcass characteristics of broiler chickens grown at high altitude. Poult Sci $\mathbf{9 0}$, $2287-2294$ 